\title{
Assessment of progressive collapse of operated buildings and structures based upon structural damage
}

\author{
S.I. Merkulov \\ Doctor of Technical Sciences, Professor of \\ Department of Industrial and Civil Engineering \\ Kursk State University \\ Kursk, Russia
}

\author{
A.I. Tatarenkov \\ Candidate of Technical Sciences, Associate Professor \\ of Department of Industrial and Civil Engineering \\ Kursk State University \\ Kursk, Russia
}

\author{
R.V. Lesovik \\ Doctor of Technical Sciences, Professor of \\ Department of Construction Materials Science, Products and Structures \\ Belgorod State Technological University named after V.G. Shukhov \\ Belgorod, Russia
}

\begin{abstract}
The paper outlines different solutions to address the problem of progressive collapse when designing buildings and structures and proposes possible modes of progressive collapse of structural systems. It presents the requirements stipulated by regulatory documents for assessing progressive collapse of buildings. It overviews some studies aimed at the evaluation of progressive collapse of structural systems. Based on the analysis and generalized provisions of normative documents and scientific research, some measures to prevent progressive collapse in design of buildings and other operated facilities are proposed.
\end{abstract}

Keywords - building structural systems, structural safety, brittle failure, progressive collapse, disproportionate collapse, corrosion damage

At present, an increased number of devastating natural and human-made disasters have caused the urgent need for applied and theoretical studies of the resistance of structural systems to progressive destruction.

The term progressive collapse was first used in the 1970s and today its definition has been offered. Basically, progressive collapse is referred to as a failure that in its final stage (resulting damage) significantly exceeds the initiating local damage that develops in a chain-like manner. The cause of progressive collapse is generally attributed to a sudden destruction of one element, which entails instant stressredistribution on other elements and eventually their collapse. This process develops as long as the structure is completely destroyed or until stress equilibrium in an undestroyed part of a building is reached. It is very important to determine the causes and paths of progressive collapse of a structure when developing methods for protecting buildings and structures. In [12], a descriptive classification of progressive collapse is given. As shown in [8], the design of structural systems with allowance for progressive collapse is possible through the limit state method that requires determination of the mode and nature of failure. The authors propose the following modes of the progressive collapse of structural systems:

- Mode 1. Sudden failure of all elements of one of the upper floors, which initiates a subsequent collapse of elements of the upper floors, resulting in a dynamic load on the floors below. Possible causes are attributed to the fall of an aircraft, snow load, gas-air explosion, fires.

- Mode 2. Failure of one of the elements of the structural system followed by stress-redistribution on adjoining elements and resulting in the collapse of these elements in a domino effect. The causes are attributed to the impact from a vehicle bumping, a local explosion, a significantly increased operational load, a repeated seismic load on a damaged building.

- Mode 3. Loss of resistance by one of the components of a structure or a structure being a segment of the structural system. The causes are attributed to a significantly increased operational load, a change in the load path as compared with the design one.

- Mode 4. Transformation of statically indeterminate truss of a building into a statically determinate geometrically variable structure due to the formation of plastic pin joints as junctions of the structures. The cause is attributed to a significant increase in the operational load.

- Mode 5. Failure of one of the elements of the structural system and (or) the loss of stability of one of the elements of the structural system and (or) the formation of plastic hinges at the couplings of the structural system under the action of the design load. The cause is attributed to some degradation processes, such as aging, corrosion and others. 
- Mode 6. Combination of the above-mentioned modes of failure caused by various impacts in aggregate.

All the proposed modes, though, have some features in common, namely, the impact of low probability event; a sudden failure of a small structural element followed by an avalanche-like collapse of the entire structural system or a significant part of it; massive damage of a structure, many times exceeding the original local damage.

Since the resulting damage significantly exceeds the initiating local destruction in terms of its extent and economic damage, the progressive collapse can be defined as disproportionate collapse. With the introduction of the term disproportionate collapse, it became possible to propose disproportionality criteria as some ultimate dimensions of the resulting damage zone. Thus, when designing building structures, strategies to limit the consequences of localised failure are specified. In accordance with [1, 2], the damage zone of load-bearing structures is localized to an area of $80 \mathrm{~m}^{2}$ on one floor, while the initial collapse level is limited to one upper or lower floor. Similar constraints on local damage zones are established in European standards [3] stipulating that the local damage zone is limited to an area of $70 \mathrm{~m}^{2}$ or $15 \%$ for each of the two adjoining floors in the event of the removal of the outer column. As stipulated by US standards [4], when removing the outer element, local floor collapse above the removed element is limited to an area of $70 \mathrm{~m}^{2}$ or $15 \%$ of the total floor area. On the contrary, when removing the internal element, the standard values are doubled. Today specialists frequently use a combined term "progressive collapse". Table 1 summarizes the list of documents containing provisions for the protection of buildings and structures against progressive collapse.

TABLE I. SUMMARIZES THE LIST OF DOCUMENTS CONTAINING PROVISIONS

\begin{tabular}{|l|l|l|l|}
\hline ADA & $\begin{array}{l}\text { Building Regulations. Approved } \\
\text { Document A. Structure }\end{array}$ & $\begin{array}{l}\text { Great } \\
\text { Britain }\end{array}$ & 1992 \\
\hline EC1 & $\begin{array}{l}\text { EN 1991-1-7. Eurocode 1. Action on } \\
\text { structures. Accidental }\end{array}$ & EU & 1998 \\
\hline GPB & $\begin{array}{l}\text { Guidelines for the protection of panel } \\
\text { apartment blocks }\end{array}$ & Russia & 1999 \\
\hline GPFB & $\begin{array}{l}\text { Guidelines for the protection of truss } \\
\text { dwellings }\end{array}$ & Russia & 2002 \\
GSA & $\begin{array}{l}\text { Progressive collapse analysis and } \\
\text { guidelines for new federal } \\
\text { buildings and major } \\
\text { affization projects. GSA }\end{array}$ & USA & 2003 \\
\hline MCS & $\begin{array}{l}\text { MCS 4.19-05 Temporary regulations } \\
\text { on mixed-up complex designs }\end{array}$ & Russia & 2005 \\
\hline RCN & $\begin{array}{l}\text { RCN 31-332-2006 Dwellings and } \\
\text { public high-rise buildings } \\
\text { resist progressive collapse }\end{array}$ & Russia & 2005 \\
\hline UFC & $\begin{array}{l}\text { UFC 4-023-03 Design of buildings to } \\
\text { USA }\end{array}$ & 2005 \\
\hline
\end{tabular}

\begin{tabular}{|l|l|l|l|}
\hline GHB & $\begin{array}{l}\text { Guidelines for the protection of high- } \\
\text { rise buildings against progressive } \\
\text { collapse }\end{array}$ & Russia & 2006 \\
\hline GMH & $\begin{array}{l}\text { Guidelines for the protection of } \\
\text { monolithic dwelling against } \\
\text { progressive collapse }\end{array}$ & Russia & 2006 \\
\hline NYBC & New-York Building Code & USA & 2007 \\
\hline TCP & $\begin{array}{l}\text { TCP 45-3.02-108 High-rise buildings. } \\
\text { Building codes }\end{array}$ & Belorussia & 2008 \\
\hline
\end{tabular}

When designing buildings and structures in such a way as to prevent progressive collapse, one should account for emergency situations yet low-probability and short-lived but leading to some limiting conditions. Such emergencies encompass explosions, accidents and (or) fires, and a loadbearing failure, currently being supplemented with a terrorist threat - explosions. So far, some researchers have proposed certain approaches and methods for assessing possible progressive collapse as well as ways to protect buildings and structures [5-9]. The general methodology for reducing the risks of progressive collapse occurred in buildings and structures is outlined. The main provisions are as follows:

- relied on safety management, warning or complete prevention of an emergency impact, for example, explosions caused by a terrorist act, namely, a design situation leading to a sudden removal of one or more elements from the structural system;

- reducing the extent of damage through a number of design methods that include creating a single structural continuity of frameworks, introducing additional ties into the structural scheme, continuously reinforcing members of monolithic steel-reinforced concrete floors, excluding brittle failure of individual members and their nodes, and others;

- preventing progressive collapse. The analysis leads to the identification of structural elements whose destruction inevitably entails a progressive collapse and causes the greatest damage to the facility, personnel and equipment. When designing, the absolute strength of this element is ensured to resist emergency loads.

First of all, it is necessary to ensure emergency prevention at the facilities where incidents can lead to numerous loss of life. This specifically concerns popular gathering points (stadiums, means of transport and others). Protection consists in building various protective barriers to restrict access of vehicles to the site, supervising visitors and other restrictive measures. Protective measures do not increase the resistance of the structural system of buildings to a progressive collapse. However they are the only possible way to avoid the collapse of the building. This particularly refers to low-rise buildings with long-span truss structures.

The most common method to protect buildings against progressive collapse is to reduce the extent of progressive collapse through containment and mitigation approaches. A truss is "split up" into separate segments (to localize collapse breaking-out) that cannot be overflown by the progressive 
collapse impact. To achieve this, a truss is horizontally broken down by contraction joints whereas braced framing or powerful floor girders are vertically arranged. Another way to reduce the extent of collapse is to introduce additional ties into the structural scheme. Thus, concerning load-bearing frames, it is recommended to execute ties along the external columns as well as vertical ties, truss ties, internal ties. To protect the designed building against progressive collapse, the loadbearing capacity of all elements of the system shall be sufficient enough to perceive initial disturbances. This approach notably increases the material consumption of the design solution. As shown in [7], the reinforcement required for the perception of the emergency impact and the loads applied exceeds 3 - 3.5 times the amount of reinforcement required to provide the bearing capacity of the structures under design loads. Thus, when considering various modes of possible progressive collapse, all possible variants of local damage are analyzed. However, it is also necessary to solve issues relating to cost effectiveness of the obtained technical solution.

\section{Variants of progressive collapse in structural systems:}

1) Local failure of a damaged structure under design loads, leading to stress-redistribution on the elements of the system, followed by possible progressive collapse of the structural system.

2) Local failure of an individual element under emergency action, leading to an avalanche-like collapse of the structural system.

3) Loss of resistance by a member of the system, leading to an avalanche-like collapse of the structural system.

4) A combination of factors leading to progressive collapse of the structural system.

Local failure of a structure under design loads, leading to stress-redistribution on the elements of the system and followed by possible progressive collapse of the structural system, possibly occurs due to degradation processes such as aging, corrosion, and others. In this case, we are talking about the failure of structures operated for a long time in conditions that reduce the design load-carrying capacity of structures.

The reasons for this bearing capacity decrease are forced damage, as well as environmental damage (corrosion, temperature, etc.). These objects were designed with no account for possible progressive collapse, consequently, to assess the local failure, it is first necessary to consistently estimate the effect of such damage, to ensure structural safety of the truss and, ultimately, to prevent possible progressive collapse $[6,10,11]$.

The toughest objective is to account for operation-related damage to prevent the progressive collapse of structural systems of steel-reinforced concrete facilities. Progressive collapse of a reinforced concrete truss with operational damage to its members is possible when exposed to design or even lesser loads. The structural system is thought to be a complex structure that is entirely hierarchical from materials of structures to the structural system as a whole: materials; components of structures; structures; nodes and points of structures; structural systems. Provided that a possible progressive collapse of the structural system is detected, a hierarchical approach is also needed to assess the scope of operational damage.

When assessing structural safety of constructed facilities, it is first necessary to take into account the corrosion-induced damage of structural materials along with a stressed state. The course of corrosive processes in concrete is determined by working stresses. Thus, to respond to compression occurred in concrete samples, the effective diffusion coefficient of carbon dioxide is reduced by an order of magnitude and increased by one or two orders of magnitude in tension. Moreover, corrosion-resistance of concrete depends on the level of compressive stresses. With compressive stresses that do not exceed the lower limit of microcrack enlargement in concrete, the porosity of concrete is markedly reduced causing the structure of concrete to be sealed, which in turn reduces the penetration rate of hazardous chemical reagents as compared with unstressed concrete. Higher compressive stresses initiate the process of formation, accumulation and development of micro failures thus loosening the structure of concrete and increasing the penetration rate of hazardous environments into the structure of concrete. Admittedly, corrosive and force influence are herein mutually reinforcing.

In steel-reinforced concrete structures, the expansion coefficients for steel and concrete have almost the same magnitude. However, subject to chemical and physicochemical corrosion, concrete expands, while steel does not show its own strains. In case of high temperature, though, steel suffers from its own strains opposite to those of concrete. In this situation, steel-reinforced concrete structures encounter specific damage and the technique to determine internal stresses in reinforced concrete, based on the equality of forces and the continuity of concrete-reinforcement strains, needs to be further improved.

Corrosion damage tends to provoke a decreased resistance capacity of structural components and assemblies in buildings. Corrosion mainly reduces a cross-section of structural elements, but apart from such obvious consequence, defects caused by aggressive environments become visible following a more complicated way. Corrosion-induced changes in the strength and strain parameters in a concrete compressive zone, corrosion of tensile reinforcement bars and consequential loss of bond stress lead to the failure to comply with the design limitations imposed on the height of the compressive zone, which results in brittle failure of bending steel-concrete structures with corrosion damage under design load. Corrosion damage brings about the formation and further expansion of cracks, a decrease in the rigidity of structures, and massive deformations. The theory of stress resistance of corrosiondamaged building structures makes it possible to assume that the impact of aggressive environments is conventionally uniformly distributed over the span and height of the crosssection of the structure. With this in mind, the stress resistance of corrosion-damaged structures is determined in the section with the greatest internal forces. However, numerous attempts to inspect structural elements of buildings subjected to aggressive environments indicate that the zones of structures with the greatest corrosion damage do not coincide with the 
areas of the greatest internal forces. The above-mentioned circumstances require more explicit theory of structural resistance, followed by the detection of risky cross-sections in terms of corrosion damage, orientation and the level of working forces.

Structural safety of constructed facilities is largely ensured by the integrity of joints and links of the structural statically indeterminate system. When designing buildings and structures, design solutions are preferable to increase the degree of static indeterminacy of the truss. Another condition to ensure structural safety of constructed facilities is to design joints not vulnerable to brittle failure [7]. Corrosion damage of joints in the truss leads to changes in the boundary conditions of elements and stress-redistribution on the elements of the structural system. In the first case, for a truss steel-reinforced concrete building with corrosion damage to its rigid beam, to column joints, the design diagram of the beam changes from rigidly pinned at both ends to the hinged beam structure, which halves the stress resistance of the beam [8]. In the second case, following the stress-redistribution on the elements, forces might arise in some members, exceeding the design load forces, and leading to unacceptable strains.

Concerning trusses of buildings and structures, structural safety is determined by the ability of the system to keep the necessary degree of static indeterminacy, ensuring the perception of design loads in the event of forced and corrosion damage to individual components, nodes and connections.

In the context of corrosion damage to the elements of the structural system or its nodes, progressive collapse schemes are implemented:

- Local failure of the damaged structure, leading to stressredistribution on the elements up to the values exceeding the ones calculated.

- Loss of structural resistance due to the failure of a structural member or node, leading to an avalanche-like collapse of the truss.

The available documents that contain provisions pertaining to the protection of buildings and structures from progressive collapse are primarily aimed at designing facilities rather than solving a similar problem typical of operated buildings and structures and do not take into account the operational damage of individual elements and joints of the truss.

A credible assessment of operational damage to steelreinforced components is possible through the structural safety theory that enables to give a generalized definition of the stress-strain state and to estimate the structural capacity in all phases of a facility life cycle, allowing for stress, environmental and time factors, technological impacts, structural transformation and other factors [13].

Further development of the theory should be considered in the following areas:

- Studying mechanisms of steel-reinforced concrete collapse due to strength and corrosion impacts, taking into account the stress level with respect to possible local failures of individual elements, causing progressive collapse of the truss.
- Developing structural safety management of buildings and structures, reflecting the genesis of structural systems, quasi-stationary performance.

- Specifying the structural safety criterion taking into account composite and forced structural control of buildings and structures.

- Eleborating the model of adaptive evolution relevant to quasi-stationary structures and structural systems.

Implementing the specified research strategies and further developing, the theory of structural safety will give opportunities to manage structural safety of facilities and address the challenge of resisting progressive collapse of trusses of operated buildings and structures.

Applied and theoretical studies show that sudden collapse of a member or connection of a structural system under operational load leads to a dynamic additional loading applied to all other elements of the system and, as a consequence, to a possible progressive collapse. In modern design methods, this phenomenon is called a dynamic effect. At present, there are some design solutions to structural systems in the event of failure of its element and possible progressive collapse. The first solution implies a high-precision non-linear dynamic calculation. The second solution implies approximate dynamic calculation in elastic-linear formulation. The third solution is a primitive calculation based on the use of equivalent static loads with the introduction of a dynamic factor. Recently, primitive calculations have become popular based on a linear static procedure that requires the application of an incremental factor to the loads, taking into account both nonlinear and dynamic effects. To estimate dynamic effect in applied calculations, the dynamic load factor is used. In many methods, the dynamic load factor is equal to 2.0 for the elastic calculation of the structural system, the value of the factor decreases if the calculation is carried out taking into account plastic strains. The introduction of the dynamic factor made it possible to simplify the dynamic effect consideration during the sudden collapse of one of the elements of the structural system, namely, to bring dynamic calculation to static. To ensure the effective application of this method, the main objective is to establish differentiated dynamic factors that take into account the performance of the structural system in case of dynamic emergencies, the nonlinear nature of material strain, and geometrically nonlinear strain of the structural system as such. The present methods to prevent progressive collapse can be divided into three groups. The first group is comprised of 'possible damage' methods. When designing buildings and structures in accordance with these methods, normal loads are calculated together with dynamic specified loads. Moreover, this takes into account changes in the strength and strain characteristics of materials under shortterm dynamic loading. In the design situation, one or more structural components in the local failure zone are not left out.

The second group is composed of methods that include 'key elements' designed to perceive specific impacts thus mitigating the occurrence of local damage, or assess the stressredistribution in the system when an element (or several elements) is removed. In both cases, the calculated stresses and displacements should not exceed the maximum 
permissible value. These methods are based on a probability approach concerning the development of progressive collapse scenario in the design phase, which appoints a 'key element' or a group of 'key elements' responsible for resisting progressive collapse. Accordingly, the task is solved only within the framework of the proposed scenario. The emergency situation that causes the local failure of an individual structure and, as a consequence, progressive collapse, is random by nature, both in the application scheme and in the magnitude of the emergency load. The application of these methods is limited, though. For instance, it is almost impossible to determine the progressive collapse of a high-rise truss building of a braced system in the event of one column being collapsed. The 'key element' method is effective when the point and value of external specified load are undoubtedly defined in the design phase, e.g. when designing a facility in one of the rooms of which the gas-air explosion might take place. Designing 'key elements' of the structural system leads to an increase in the material consumption of the design solution.

The third group of methods restricts the local failure zone due to the removal of an element (or several elements) by structural methods, i.e. setting up a system of horizontal and vertical links. A more detailed description of these design methods is given in [5]. They imply the construction of braced floors in trusses of high-rise buildings, the use of powerful bottom chords as well as vertical and horizontal links in the beams with spotfacing the connections in adjoining structures. A method of separating structural systems is also known when statically indeterminate structural systems of a frame building are divided into independent blocks by hinged inserts. In this case, if one element is destroyed, the dynamic effect is localized within one block.

The described methods to resist progressive collapse can be applied to highly dangerous, technically complex and unique facilities. On the other hand, as reflected in [5], taking into account emergency risks, it is justified to protect residential and public buildings against possible progressive collapse. The most probable case of progressive collapse in residential buildings is the collapse of slabs. When designing a plate support unit in joints, it is necessary to ensure the safety of the unit when exposed to possible emergency loads.

The analysis showed that protection of structural systems from progressive collapse is undertaken in three main directions: mitigating emergency risks to an acceptable level; ensuring the absolute load-bearing capacity of the 'key element' to perceive specific impacts; localizing the extent of progressive collapse by removing a single element of the local zone. These methods do not enable one to address the problem of truss progressive collapse of operated facilities if failures take place. Taking into account the specific nature of the issues under consideration, the design methods require some appropriate improvements.

\section{Acknowledgment}

The work was carried out within the framework of the implementation of the Program for the Development of a Flagship University on the basis of BSTU named after V.G. Shukhov.

\section{References}

[1] MCS 4.19-05 "Multifunctional high-rise buildings and complexes" - M $\therefore$ Department of Urban Development Policy, Development and Reconstruction of Moscow, JSC Central Research Institute for the Study of the Environment, 2005, p.70.

[2] MCS 4.19-2005 "Temporary rules and regulations. Designing multifunctional high-rise buildings and building complexes in Moscow. " - Enter. 2005-12-28. Moscow: The Government of Moscow, Moscomarchitecture, 2005.

[3] EN 1991-1-7 Part 1-7: «General Actions - Accidental actions». CEN. 2003, pp. 69.

[4] UFC 4-023-03. «Design of buildings to resist progressive collapse». DepartmentofDefense, 2003, 176 p.

[5] V.O. Almazov, KhoiKao Zui. "Dynamics of the progressive collapse of monolithic multi-storey frameworks." Monograph, M .: Publisher AAU, 2013, pp.128.

[6] A.G. Tamrazyan, "Mitigating risks in construction in emergency situations of natural and man-made nature, Scientific publication. Ed. A.G. Tamrazyan, M .: Publisher AAU, 2012, pp.304.

[7] Yu.P. Nazarov, A.S. Gorodetsky, V.N. Simbirkin. "To the problem of ensuring the survivability of building structures under emergency influences". Construction mechanics and design, №4, pp.5-9, 2009.

[8] S.I. Merkulov, "Vitality of reinforced concrete structures and structural systems," Bulletin of the Belgorod State Technological University named after V.G. Shukhov, №3, pp. 58-61, 2015.

[9] S.I. Merkulov, "On the issue of ensuring the survivability of reinforced concrete structures and structural systems." Construction and reconstruction, №2 (58), pp. 63-67, 2015.

[10] S.I. Merkulov, R.V. Lesovik, A.A, Metrohin, N.V. Kalashnikov, "Development of Theory of Structural for Buildings and Construction," World Applied Sciences Journal, Vol. 31, № 4, pp. 531-533, 2014

[11] S.I. Merkulov, R.V. Lesovik, S.V. Klyuev, N.V. Kalashnikov, "Development of Theory of Structural for Buildings and Construction," WorldAppliedSciencesJournal, Vol. 25, № 12, pp. 1747-1750, 2013.

[12] U. Starossek, "Typology of progressive collapse," Hamburg University of Technology (TUHH). Hamburg. Germany. Engineering Structures, Vol. 29., №9, pp. 2302-2307, Sept. 2007.

[13] S.I. Merkulov, Fundamentals of the theory of reinforced concrete reconstruction, Scientific Publication. Kursk: Publishing house Kursk State Technical University, 2009. 